\title{
Dialectal Forms During Discourse of Poor, Urban, African American Preschoolers
}

Julie A. Washington Holly K. Craig University of Michigan Ann Arbor

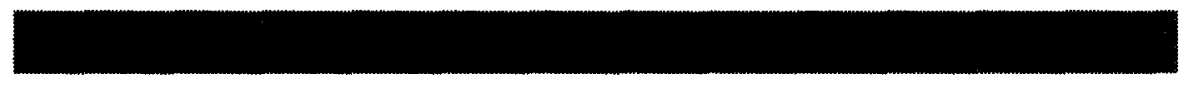

This study describes nonstandard syntactic and morphological forms used by 45 poor, urban, 4- to 5.5-year-old African American boys and girls. Distributional analyses revealed three subgroups distinguished by the percentage frequencies of occurrence of utterances containing specific forms, and by the predominant types used by each group. Implications for characterizing the linguistic productions of young African American children are discussed.

KEY WORDS: preschoolers, African American English, cultural dialects, normal language

The population of most large urban centers in the United States includes a significant number of African American residents, many of whom live below the poverty line (Cole, 1980; University of Michigan Detroit Area Study, 1989; Statistical Abstract of the United States, 1990). The sheer size of this ethnic group and its growing numbers create a sense of urgency for increasing our understanding of the linguistic knowledge and language use of this population. Clinical management of speech and language disorders with African American children presents a special challenge to educators and speech-language clinicians because of the well-documented use of cultural dialect forms that differ markedly from Standard English (SE) and the lack of norm-referenced information available for this population.

The language used by many African American adults and children has been referred to variously as "black dialect," "Negro nonstandard English," "black English vernacular," "ebonics," and "black English." As Terrell and Terrell (1993) note, the rationale for these changes in terminology has typically reflected changes in racial name identification or shifts in the priorities of language studies. In recent years a gradual shift from the use of the identifier "Black American" to the use of "African American" has occurred. Accordingly, the term African American English (AAE) has been adopted for use in this study to refer to the language system as a whole. The term $A A E$ forms is used here to refer only to the syntactic and morphological characteristics identified for examination in this investigation.

Much of what we know about the linguistic characteristics of African American English is based upon the study of adolescent and adult speakers at a time when the experimental focus was to establish AAE as a language system in its own right as opposed to a deficient form of SE (Dillard, 1972; Fasold \& Wolfram, 1970; Stewart, 1970; Wolfram, 1971; Wolfram and Fasold, 1974). The AAE forms derived from the study of these adolescents and adults have been applied to examination of the productions of young children. The earliest of these investigations were those conducted by Baratz (1970). Baratz compared the list of syntactic and morphological forms of AAE identified for adults to the utterances of low-income, preschool-age children and confirmed that African American children were using the same AAE 
forms as African American adults in their communities. Since these early reports, however, few empirical studies have appeared that systematically address language use or acquisition in children who are speakers of AAE. Two notable exceptions are the works by Stockman and Vaughn-Cooke (Stockman \& Vaughn-Cooke, 1982, 1984; Stockman, 1984) and Nelson (Nelson, 1993; Nelson \& Hyter, 1990). The former applied Bloom and Lahey's (1978) content-form-use analysis and the latter Lee's (1974) Developmental Sentence Scoring to the language analysis of young African American children. Both of these applications would be improved, however, if information about typical AAE form use by children of this population were available. Other studies of AAE use by children have been preliminary in nature or unpublished (Blake, 1984; Bridgeforth, 1984; Cole, 1980; Kovac, 1980; Reveron, 1978; Steffensen, 1974; Stokes, 1976).

Comparing the linguistic productions of young children to an adult model has merits when no other starting point is available. Early scholars in child language used Chomsky's theory of transformational grammar (1957) as a starting point and identified what young children were doing the same or differently (Brown, 1973; Brown, Cazden, \& Bellugi, 1968/ 1973; Klima \& Bellugi, 1966/1973; Lee, 1974; McNeill, 1970; Miller \& Ervin-Tripp, 1964/1973). Bloom and Lahey (1978) described this adult-driven approach to studying language as an "etic" approach that accords the researcher initial access into the child's language system. Miller and Ervin-Tripp (1964/1973) suggested that before it is possible to describe the development of grammar in children, it is necessary to understand the characteristics of language used by adults, because the adult model represents the eventual outcome of the child's development. By implication, a first step in investigating AAE would be to make comparisons to an adult model.

Describing childrens' language use and development based entirely upon the adult model, however, results in an incomplete and perhaps misleading picture of the young child's abilities (Bloom \& Lahey, 1978). Children's linguistic productions represent a unique system governed by its own rules, which may or may not be present in the adult language system. Bloom and Lahey (1978) suggested that in order to truly characterize the child's knowledge, it is necessary to progress to an "emic" approach, in which the child's own linguistic competency becomes the focus rather than the child's abilities relative to an adult model. Bloom and Lahey propose a transitional set of analyses, an etic-emic approach, in which a priori adult behaviors define the analysis system, but the unique distributional properties of children's usage are the descriptive outcome. Whereas the adult model is still the starting point, it is the eventual endpoint that has changed. The goal is to define the child's linguistic performance on the basis of trends or patterns identified that exist apart from those presented by an adult model. The earliest attempts at describing child language using an etic-emic analysis demonstrated the power of this approach (Bloom \& Lahey, 1978; Braine, 1963; McNeill, 1970).

The purpose of this investigation was to begin to characterize the linguistic productions of 4- and 5-year-old African American children based upon the distributional relationships of AAE forms identified from the extant literature for adults. Specifically, this investigation focuses upon characterizing syntactic and morphological dialect forms identified in the subjects' connected speech.

The following research questions were posed.

1. What percentage of utterances in the language samples of low-income African American preschoolers contain selected AAE forms?

2. How many different AAE forms characterized the samples of each of the subjects?

3. How common are the AAE forms across subjects?

\section{Method}

\section{Subjects}

The subjects were $\mathbf{4 5}$ urban, African American preschool boys and girls from low-income households. Children in this investigation ranged from approximately 4 to 5.5 years of age. Children of these ages were selected because Cole (1980) failed to find substantial AAE use in children 3 years of age and younger and suggested that this was due to their linguistic immaturity. Further, preschoolers were selected because there is little information available about this age group and because they should still be relatively free from the effects of formal exposure to SE that is represented by classroom instruction.

All of the children were enrolled in the same "at risk" preschool program in a Metropolitan Detroit area public school system. Several criteria were used by the school system to establish a child's "at risk" status. These included low family income, which was verified using documents obtained from the State. Department of Social Services. None of the children were medically at-risk, and based upon teacher reports all were functioning appropriately in the classroom and were not receiving special education senvices.

The preschool program in which the subjects were enrolled consisted of $\mathbf{3 9 6}$ children, 250 of whom were African American. The preschool was operated using a traditional half-day preschool model. Subjects were randomly selected from both the morning and afternoon preschool classes.

All of the subjects in this study were part of a larger project in which additional children participated. Twenty-eight of the African American children enrolled in the preschool were characterized by the teachers as "poor communicators" in the classroom, and they participated in a different data collection procedure (see Washington \& Craig, 1992a for additional information about this subset). The remainder were stratified by gender and then randomly selected until a sample of 62 children were identified who were not considered poor communicators and had unremarkable medical histories. One male child was subsequently removed from the sample after a teacher reported that despite the absence of clinical records, fetal alcohol syndrome was suspected by the school social worker. Of the 61 potential preschoolers identified in this manner, freeplay language samples were available for analysis from 45 subjects. Three potential subjects were lost because of a lack of responsiveness in that context. Samples were unavailable from the other po- 
tential subjects because of subject attrition or a noisy recording environment on one day of data collections. Each of the 45 subjects passed a bilateral hearing screening at $25 \mathrm{~dB}$ for 500,1000 , and $4000 \mathrm{~Hz}$ (ANSI, 1969) administered before data collection.

Informal observation of the preschool environment revealed that the teachers used SE during classroom instruction. However, the teachers' aides, who were the childrens' parents or grandparents, used AAE when interacting with the children, suggesting that AAE was typically used by family members when interacting with the children.

\section{Data Collection}

The data collection protocol involved collecting an approximately 20-min language sample from each child during freeplay. This was part of a larger sampling procedure that included collection of an approximately 10-min more structured language sample of each child describing a set of 10 action pictures.

The order of administration of each of these was randomly determined for each subject. Inspection of the outcomes of this project revealed that the data trends were unaffected by the order in which the children participated in these sampling contexts.

The freeplay language samples were collected during adult-child discourse in a classroom at the preschool. The examiners were three African American female adults, who were users of both SE and AAE. The examiners' ability to code-switch between the use of SE and AAE was observed during informal interactions with African American adults before data collection. Each examiner was instructed to use AAE forms while interacting with the subjects. Transcription of the adult and child utterances revealed that the examiners used AAE forms during the freeplay data collections.

The language samples were audio-recorded using a Sharp professional audiorecorder with an internal microphone. The adult and child wore Telex wireless lapel microphones as well so that the child was able to move freely around the play area. Three different action toy sets were presented to each subject and, in order to ensure a comparable level of interest across subjects, s/he was instructed to choose one set with which to play during the freeplay interaction. The toy sets were (a) Barbie and Ken dolls with a Burger King play set; (b) Ghostbuster action figures, cars, and equipment; and (c) the Fisher-Price School set. The play sessions produced approximately 15 hours of interaction and 4,052 total utterances for analysis.

\section{Scoring and Data Analysis}

Each child's language sample was transcribed first in draft form by project staff and then checked for accuracy by one of the experimenters who was African American and familiar with AAE. The childrens' discourse was segmented into utterances that were defined as any production determined to be independent on the basis of intonation and pause patterns (Miller, 1981). Utterances consisted of both single and multiword productions, including stereotypic acknowledgments such as "uh huh" or " $\mathrm{mm} \mathrm{hm."}$

Each child's utterances were examined and scored for the presence of 17 morphological and syntactic AAE forms. Consistent with the etic-emic approach described by Bloom and Lahey (1978), adult AAE forms that have been described in the literature were used as a starting point for examination of the childrens' utterances. The transcripts were examined further for the presence of dialectal forms that have not been discussed in the adult literature. Distributional analyses were then performed in order to identify patterns of AAE form use by these child subjects.

Each form and an example are presented in Table 1. Examples of utterances containing comparable lexical items that were not scored as AAE are also presented where appropriate.

Three lexical items that have not been discussed in the adult literature were included in the scoring taxonomy. These were abbreviated pronunciations of "fixing to," "supposed to," and "about to," respectively. Each functioned as a way to code imminent action: fitna (e.g., "she fitna backward flip"), sposeta (e.g., "when does it sposeta go"), bouta (e.g., "they bouta drown or something"). It was interesting also that when these linguistic forms were used to express imminent action, the phonetic shape of the utterances was distinctive, so that the forms fitna, sposeta, and bouta were spoken as catenatives. Examples of utterances that were not scored for this AAE form included "they fixin the house," "what are we supposed to do to that," "what about they lunch."

It was possible for AAE forms to co-occur in an utterance. Of the utterances that contained AAE forms, 611 had only one and 92 contained form co-occurrences. All tokens were scored regardless of the number of types they reflected; a type analysis was performed separately. Following are two examples of utterances in which more than one type occurred. The scoring for each utterance is indicated in parentheses. In the second example the same type (deletion of auxiliary) was used twice in the same utterance and was scored accordingly. "them people waitin'
on the bus"

"people gettin on a elevator and people gettin off of it" (undifferentiated pronoun case; zero auxiliary)

(zero auxiliary; indefinite article; zero auxiliary)
Some utterances containing zero AAE forms could have been scored using alternative AAE forms, depending upon the examiner's interpretive gloss. In these instances the contiguous discourse was used to select one interpretation over another. In the following example, zero "ing" was scored in the second utterance because either present or past tense seemed possible but the preceding utterance was in the present progressive form.

$$
\begin{aligned}
& \text { "and it's a squirrel runnin' around" } \\
& \text { "and it's a kid open up a case" }
\end{aligned}
$$

Reliability. Ten percent of the utterances of every subject were randomly selected for retranscription. Point-to-point 
TABLE 1. The morphological and syntactic AAE forms* scored for each subject.

\begin{tabular}{|c|c|}
\hline Definition & Examples \\
\hline $\begin{array}{l}\text { Zero copula or auxiliary** } \\
\text { is, are, and modal auxiliaries: will, can, and } \\
\text { do are variably included }\end{array}$ & $\begin{array}{l}\text { "the bridge out" } \\
\text { "how you do this" }\end{array}$ \\
\hline $\begin{array}{l}\text { Subject-verb agreement } \\
\text { A subject and verb that differ in either number } \\
\text { or person }\end{array}$ & "what do this mean" \\
\hline $\begin{array}{l}\text { Fitna/sposeta/bouta } \\
\text { Abbreviated forms of "fixing to," "supposed } \\
\text { to," and "about to," coding imminent action. } \\
\text { (Examples of utterances that were not } \\
\text { scored for this form were: "they fixin it," } \\
\text { "what are we supposed to do to that," } \\
\text { "what about they lunch?") }\end{array}$ & $\begin{array}{l}\text { fitna: "she fitna backward flip" } \\
\text { sposeta: "when does it sposeta go" } \\
\text { bouta: "this one bouta go in the school" }\end{array}$ \\
\hline $\begin{array}{l}\text { Ain't } \\
\text { "ain't" as a negative auxiliary }\end{array}$ & "why she ain't comin?" \\
\hline $\begin{array}{l}\text { Undifferentiated pronoun case } \\
\text { Nominative, objective, and demonstrative } \\
\text { cases of pronouns occur interchangeably }\end{array}$ & "him did and him" \\
\hline $\begin{array}{l}\text { Multiple negation } \\
\text { Two or more negative markers in one } \\
\text { utterance }\end{array}$ & "I don't got no brothers" \\
\hline $\begin{array}{l}\text { Zero possessive }{ }^{\star *} \\
\text { Possession coded by word order so that the } \\
\text { possessive }-s \text { marker is deleted, or the } \\
\text { nominative or objective case of pronouns is } \\
\text { used rather than the possessive }\end{array}$ & $\begin{array}{l}\text { "he hit the man car" } \\
\text { "kids just goin' to walk to they school" }\end{array}$ \\
\hline $\begin{array}{l}\text { Zero past tense } \\
\text {-ed is not always used to denote regular past } \\
\text { constructions, or the present tense form is } \\
\text { used in place of the irregular past form }\end{array}$ & $\begin{array}{l}\text { "and this car crash" } \\
\text { "and then them fall" }\end{array}$ \\
\hline $\begin{array}{l}\text { Zero -ing }{ }^{\star \star} \\
\text { Present progressive morpheme -ing is } \\
\text { deleted }\end{array}$ & "and the lady is sleep" \\
\hline $\begin{array}{l}\text { Invariant be } \\
\text { Infinitival be with a variety of subjects coding } \\
\text { habitual action ("it's gonna be far away" } \\
\text { was an example of when habitual be was } \\
\text { not scored); or to state a rule }\end{array}$ & $\begin{array}{l}\text { "and this one be flying up in the sky" } \\
\text { "if he be drunk I'm taking him to jail" }\end{array}$ \\
\hline $\begin{array}{l}\text { Zero to } 0^{\star \star} \\
\text { Infinitive marker to is deleted }\end{array}$ & "now my turn shoot you" \\
\hline $\begin{array}{l}\text { Zero plural }{ }^{\star \star} \\
\text { Variable inclusion of plural marker }-s\end{array}$ & "ghost are boys" \\
\hline $\begin{array}{l}\text { Double modal } \\
\text { Two modal forms for a single verb form }\end{array}$ & "I'm is the last one ridin on" \\
\hline $\begin{array}{l}\text { Regularized reflexive } \\
\text { Reflexive pronouns "himself" and } \\
\text { "themselves" are expressed by "hisself" } \\
\text { and "theyself" }\end{array}$ & "he stands by hisself" \\
\hline $\begin{array}{l}\text { Indefinite article } \\
\text { "a" regardless of vowel context }\end{array}$ & "Branda had to play for a hour, didn't he?" \\
\hline $\begin{array}{l}\text { Appositive pronoun } \\
\text { Both a pronoun and a noun reference the } \\
\text { same person or object }\end{array}$ & "the teacher she's goin' up here" \\
\hline $\begin{array}{l}\text { Remote past "been" } \\
\text { "been" is used to mark action in the remote } \\
\text { past. ("HI, what you been doing" is an } \\
\text { example of an utterance containing "been" } \\
\text { that was not AAE form.) }\end{array}$ & no examples of this form were found \\
\hline
\end{tabular}




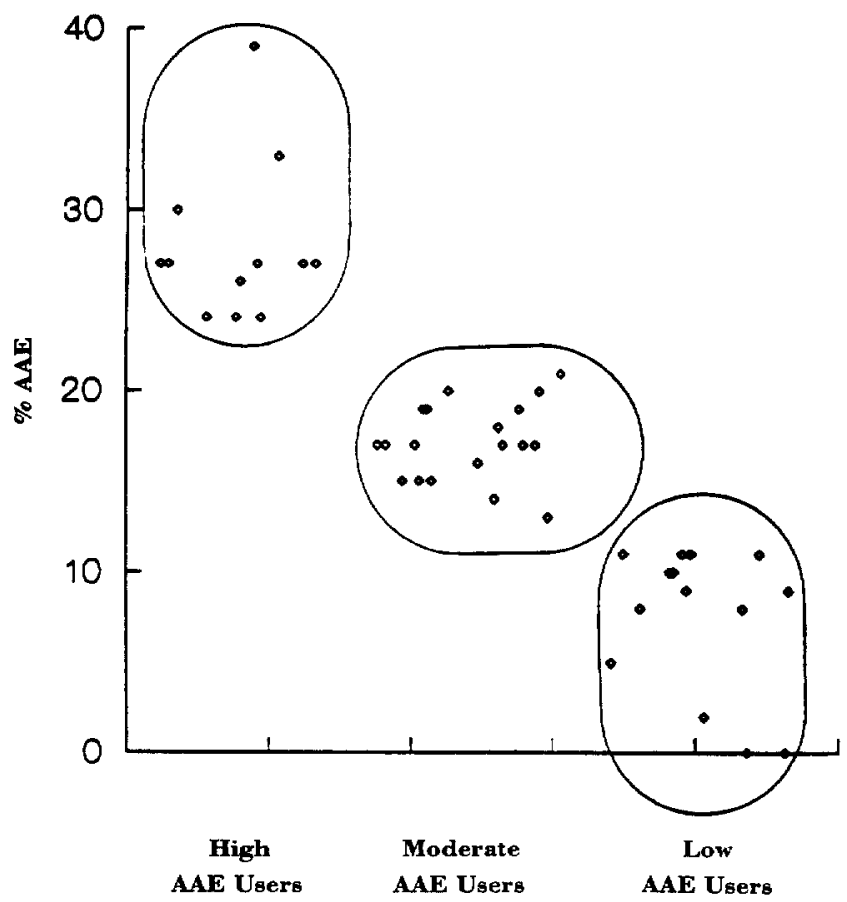

FIGUAE 1. The 3 subgroups of AAE Users.

inter-rater reliability was high at $95 \%$ agreement for utterance segmentation, and $87 \%$ for morpheme counts.

Ten percent of the samples were then randomly identified for re-scoring and all utterances in these samples were re-scored. Inter-rater scoring reliability was also high at $96 \%$ for agreement on the presence of an AAE form, and $87 \%$ for specification of the AAE form.

\section{Results}

Of the total utterances for all subjects, $703(17 \%)$ contained an AAE form. The level of AAE, defined as the percentage frequencies of occurrence of utterances containing at least one AAE form, varied considerably across subjects, from 0 to $39 \%$. Visual inspection of the data suggested the presence of two or three subgroups of AAE users: those who used nonstandard forms infrequently and those who exhibited moderate to high levels of AAE use across utterances.

In order to help distribute the data in a systematic way, a hierarchical cluster analysis with complete linkage (Johnson, 1967) was applied to the data using Systat (Wilkinson, 1988). Cluster analysis is a multivariate analysis procedure designed to detect natural groupings in data. It is an exploratory procedure that groups subjects using the distance-based "nearest neighbor" criterion (Woods, Fletcher, \& Hughes, 1986). The results of this analysis supported the initial impression that the data distributed into three distinct groups of AAE users. A scatterplot of the cases with the groups outlined is displayed in Figure 1.

The first group, a High AAE-user group $(n=12)$, exhibited levels of AAE forms that ranged from 24 to $39 \%$; the second group $(n=19)$, designated the Moderate AAE-user group,
TABLE 2. Mean $(M)$ percentage frequencles and standard deviations (SD) of utterances with AAE forms for each group, and for the groups combined.

\begin{tabular}{lcccc}
\hline & \multicolumn{4}{c}{ Groups } \\
\cline { 2 - 5 } & $\begin{array}{c}\text { High } \\
(n=12)\end{array}$ & $\begin{array}{c}\text { Moderate } \\
(n=19)\end{array}$ & $\begin{array}{c}\text { Low } \\
(n=14)\end{array}$ & $\begin{array}{c}\text { Combined } \\
(n=45)\end{array}$ \\
\hline$M$ & 27.9 & 17.2 & 7.5 & 17.0 \\
$S D$ & 4.3 & 2.2 & 4.1 & 8.5 \\
Range & $24-39$ & $13-21$ & $0-11$ & $0-39$ \\
\hline
\end{tabular}

ranged from 13 to $21 \%$; and the third group, the Low AAE-user group, consisted of subjects $(n=14)$ whose levels of AAE ranged from 0 to $11 \%$ (see Table 2).

A one-way ANOVA of arcsine transformed percentage frequencies of occurrence was applied to the data to confirm that the three groups of AAE-users performed differently. As expected, the results revealed a statistically significant difference between the groups in the percentage of AAE forms produced across utterances $[F(42)=55.9, p<.01]$. A Tukey HSD post hoc analysis confirmed that the differences among all the groups were significant $(p<.01)$.

The three groups were examined for similarities or differences in performance and subject status that might further explain group membership. Pearson product-moment correlations were calculated for each group in order to determine whether the age of the subjects or variations in opportunities due to differences in utterance corpora significantly influenced group memberships. The results revealed a nonsignificant correlation between amount of AAE and age $(r=.12$, $p>.05)$ or utterance opportunities $(r=.16, p>.05)$. An independent $t$-test was calculated to determine whether the amount of AAE was influenced by gender. Three independent $t$-tests of arcsine transformed percentages revealed that the relationship between these two variables was statistically nonsignificant in each group [High-User: $t(10)=2.06, p>$ .05; Moderate-User: $t(17)=1.44, p>.05$; Low-User: $t(12)$ $=0.33, p>.05]$.

The above analyses used tokens as their base. Types of AAE were also examined. The number of different AAE types used by the subjects ranged from 0 to 7 , with a mean of 4.3 and a standard deviation of 1.9. There was no direct relationship between the number of different types used and the percentage of utterances containing AAE forms in the language sample overall. For example, the subject with the highest percentage of AAE forms in his sample (39\%) produced 7 different types, whereas another subject whose sample contained only $17 \%$ also produced 7 different types.

The groups did differ, however, in the distributions of the 17 AAE types. (See Table 3.) This was determined by calculating the percentage frequencies of occurrence of each type within groups and then comparing the results across groups. In the High AAE-User group and the Moderate AAE-User group two types, zero copula/auxiliary and subject-verb agreement, were produced by all subjects. These two types were also the most prominent types produced in the Low AAE-User group. However, approximately one-quarter of the subjects in this group did not produce these two types at all. Further, two additional types, fitna/sposeta/bouta and ain't, 
TABLE 3. Percent of subjects using each AAE type.

\begin{tabular}{|c|c|c|c|c|c|c|c|c|c|c|c|c|c|c|c|c|c|}
\hline Groups & \multicolumn{17}{|c|}{ AAE Type } \\
\hline $\begin{array}{l}\text { High } \\
\qquad(n=12)\end{array}$ & 100 & 100 & 50.0 & 50.0 & 41.6 & 41.6 & 41.6 & 25.0 & 25.0 & 25.0 & 8.3 & 16.7 & 0 & 8.3 & 8.3 & 8.3 & 0 \\
\hline $\begin{array}{l}\text { Moderate } \\
\quad(n=19)\end{array}$ & 100 & 100 & 47.4 & 26.3 & 36.8 & 21.0 & 21.0 & 21.0 & 21.0 & 5.3 & 21.0 & 10.5 & 15.8 & 0 & 0 & 0 & 0 \\
\hline $\begin{array}{l}\text { Low } \\
\qquad(n=14)\end{array}$ & 78.6 & 71.4 & 28.6 & 14.3 & 7.1 & 21.4 & 21.4 & 28.6 & 14.3 & 0 & 0 & 0 & 7.1 & 0 & 0 & 0 & 0 \\
\hline
\end{tabular}

were produced by half of the subjects in the High AAE-User group. The other types occurred with varying frequencies across groups.

One type, remote past been, was not produced by any of the subjects in this investigation. The use of fitna, sposeta, and bouta to code imminent action, a type not drawn from the adult literature, was evident by subjects in all three AAE User groups.

\section{Discussion}

This study examined syntactic and morphological aspects of the productions of young African American children. The most striking aspect of the data was the wide variation across individuals observed both for the percentage frequencies of utterances containing AAE forms ( $0-39 \%)$ and the number of different form types (0-7).

Both amounts of AAE (percentage frequencies occurring within utterances) and types of AAE (number of different forms used per subject) related to subject groupings. Three distinctive clusters of subjects were apparent using exploratory multivariate techniques that yielded statistically significant groupings for amounts of AAE. These groupings were distinctive from each other in terms of types as well as AAE tokens. The three subgroups can be characterized as follows.

High AAE-User Group. The subjects' samples included AAE tokens in 24 to $39 \%$ of utterances. Two AAE types were produced by every subject in this group: zero copula/auxiliary and subject-verb agreement.

Moderate AAE-User Group. Their samples included AAE tokens in 13 to $21 \%$ of utterances. Zero copula/auxiliary and subject verb agreement were also produced by all of the subjects in this group.

Low AAE-User Group. They used AAE tokens in 0 to $11 \%$ of their utterances. Although zero copula/auxiliary and subject-verb agreement were the most frequent types used by these subjects as well, approximately one quarter of the group never used them.

It is interesting that two AAE types were produced by all of the subjects in two of the AAE-User groups, and by only three quarters of subjects in the third group. In addition, two more AAE types, ain't and fitna/sposeta/bouta, were produced by at least half of the subjects in the High AAE-User group. No feature reached or exceeded the $50 \%$ mark in the other two groups except zero copula/auxiliary and subject-verb agreement. The present study provides no clear explanation for these differences in distribution of types. Perhaps zero copula/auxiliary and subject-verb agreement have more opportunities to occur given that they operate on simple sentence structures and are subcomponents of major verb constituents. Although the design of the present study controlled for opportunities in a general sense by converting numbers of AAE forms to percentages of utterances, no such controls were possible for the specific types. Future research that probes specific form-function relationships will be necessary to examine the role of relative opportunities as a potential explanation.

The zero copula/auxiliary and subject-verb agreement were also the most frequent forms observed in some of our previous work with other children. Craig and Washington (1986) examined turn-taking behaviors by six normally developing African American 4-year-old boys and girls from middle socioeconomic status (MSES) backgrounds. All six children used these same two types of AAE as their primary forms during connected speech. The predominance of these types of AAE forms for children of different socioeconomic status (SES) suggests that these forms may be basic to the linguistic system and may not be susceptible to differences in subject status. In contrast, however, Ratusnik and Koenigsknecht (1976) found that SES did influence amounts of AAE in children's discourse. However, the majority of AAE types investigated were phonological rather than syntactic or morphological. Perhaps SES affects only specific types of AAE use. It will be important for future research to examine types of AAE for systematic differences related to SES.

Nonlinguistic variables may be contributing to individual differences as well. In the present study, chronological age and gender were found to be unrelated to individual subject variations, but other status variables may be involved that are unknown at this time. Terrell and Terrell (1993) suggested that there might be a "continuum" of AAE use that is influenced by contextual and status variables, such as age, 
geographic location, income, occupation, and education. It is unclear whether these variables might have influenced group membership in this investigation and, if so, to what extent. The identification of three distinct clusters of AAE users, however, lends empirical support to Terrell and Terrell's continuum hypothesis. Although the subjects were grouped into clusters statistically, their use of AAE tokens can be characterized as representing a continuum of AAE use that ranged from 0 to $39 \%$. In this sense, the clusters may represent subgroupings on a continuum, and each subject's relative order within this continuum may be influenced by other unknown status variables. This research design controlled some possibilities noted in previous literature, particularly subject differences in SES (Ratusnik \& Koenigsknecht, 1976), general exposure to SE (Bountress, 1983), and the geographic location of the subjects (Cole \& Taylor, 1990; Washington \& Craig, 1992a), but others await investigation.

The identification of three distinctive groups in this investigation raises interesting questions about how best to conceptualize the linguistic system used by African Americans. The various terms (e.g., "black English" and "black dialect") that have been used to refer to this linguistic system imply two different theoretical viewpoints. The terms "(Black) English" and "ebonics" suggest a separate language that shares so few rules with English that it can be characterized as a qualitatively different language system (Bailey \& Maynor, 1989; Taylor, 1988; Wolfram, 1987). The term "(Black) dialect," on the other hand, assumes a variation from English that shares most of its rules but also contains systematic differences (Taylor, 1988).

What evidence is there in the present investigation to support the theoretical perspective that AAE use reflects a dialect? One kind of evidence might be systematic use of nonstandard forms but in a distributional relationship with SE such that the SE forms predominate. Another kind of evidence might be special linguistic constraints on the use of lexical items common to the two linguistic systems. Most subjects $(92 \%)$ were either Moderate or Low AAE-users so that just over a third of their utterances involved forms that were different from SE. Therefore most utterances reflected $\mathrm{SE}$, in distributional terms suggestive of a dialectal variation. Forms to express imminent action that have not been discussed in the literature for adults and adolescents were used by the children in this sample and expressed by the lexical items fitna, sposeta, and bouta. Fitna, sposeta, and bouta were apparently abbreviated forms of "fixin' to," "supposed to," and "about to," respectively. The subjects' language samples also contained examples of "fixin," "about," and "supposed to" that were more consistent with SE-usage, as in the following utterances: "The people fixin' the house up with wood." "You talkin' about the door?" and "What are we supposed to do about that?" Whereas the use of these forms in SE is clearly different from that represented by imminent action, these examples indicated that the SE uses of these individual lexical items were also a part of the childrens' repertoires. The special way in which subjects used fitna/ sposeta/bouta to code imminent action provides additional support to the view that AAE is not a deficient imitation of SE but has its own linguistic properties.

Although forms to express imminent action as used by the subjects in this study have not been specified in the literature for this population, Nelson and Hyter (1990) noted the use of fitna by children in their subject sample. More than half of Nelson and Hyter's subjects resided in the same midwestern state in which our subjects resided. It is possible, therefore, that these forms represent a regional dialectal usage. It is also possible, however, that because the literature does not discuss the productions of young African American children these are unique child forms. Future research that focuses upon specific feature use in young children should explore this further.

On the other hand, what evidence is there in the present investigation to support the idea that $A A E$ use reflects more than a dialect-in particular, a qualitatively different language system? The systematic relationship between the AAE groups and the types of forms characterizing use by members of each group are consistent with the theoretical interpretation of a distinct language system. Further examination of both qualitative and quantitative aspects of AAE forms is necessary to inform future linguistic theory development.

One type of AAE not observed in the samples of any of these subjects is the remote past been, as described by Taylor (1988) and Wolfram (1971). Unfortunately, not only is descriptive information lacking for African American children, but information about language acquisition is lacking as well. It is not clear whether this AAE form is an early or late acquisition. Perhaps it was not used by the subjects in this study because it had not yet been acquired. Another possibility, however, is that the freeplay context did not require use of the remote past and the complete absence of "been" was due to sampling error. Future research will be needed to replicate the current findings and to explore developmental constraints on specific form use.

Overall, the methodology used in this investigation was successful in characterizing linguistic productions in a sample of low-income, urban, African American children. The patterns that were identified using a distributional analysis could not have been predicted from the extant literature. This methodology is recommended, therefore, in future research examining language production in this population.

\section{Acknowledgments}

The authors wish to thank Minnie O. Phillips, Barbara Crandall, and the children and parents for their cooperation and participation in this project. The data collection was supported in part by a Biomedical Research Support Grant administered by the Office for the Vice President for Research at the University of Michigan.

\section{References}

American National Standards Instltute. (1969). Specifications for audiometers (ANSI S3.6-1969). New York: American National Standards Institute.

Balley, G., \& Maynor, N. (1989). The divergence controversy. American Speech, 64, 12-39.

Baratz, J. C. (1969). A bi-dialectal task for determining language proficiency in economically disadvantaged negro children. Child Development, 40, 889-901.

Baratz, J. C. (1970). Educational considerations for teaching stan- 
dard English to Negro children. In R. W. Fasold and R. W. Shuy (Eds.), Teaching Standard English in the inner-city. (pp. 223-231) Washington, DC: Center for Applied Linguistics.

Blake, I. K. (1984). Language development in working-class Black children: An examination of form, content, and use. Unpublished doctoral dissertation, Columbia University, New York.

Bloom, L., \& Lahey, M. (1978). Language development and language disorders. New York: John Wiley and Sons.

Bountress, N. G. (1983). Effect of segregated and integrated educational settings upon selected dialectal features. Perceptual and Motor Skills, 57, 71-78.

Bralne, M. D. S. (1963). The ontogeny of English phrase structure: The first phase. Language, 39, 1-13.

Bridgeforth, C. (1984). The development of language functions among Black children from working class families. Paper presented at the pre-session of the 35th Annual Georgetown University Round Table on Language and Linguistics, Georgetown University, Washington, DC.

Brown, R. (1973). A first language. Cambridge, MA: Harvard University Press.

Brown, R., Cazden, C., \& Bellugi, U. (1973). The child's grammar from I to III. In J.P. Hill (Ed.), Minnesota symposia on child psychology, Vol. 2 (pp. 28-73). Minneapolis: University of Minnesota Press. (Original work published 1968).

Chomsky, N. (1957). Syntactic structures. The Hague: Mouton.

Cole, L. (1980). Developmental analysis of social dialect features in the spontaneous language of preschool Black children. Unpublished doctoral dissertation, Northwestern University, Evanston.

Cole, L., Taylor, O. L (1990). Performance of working class African-American children on three tests of articulation. Language, Speech, and Hearing Services in Schools, 21, 171-176.

Craig, H., \& Washington, J. (1986). Children's turn-taking: Social linguistic interactions. Journal of Pragmatics, 10, 35-59.

Dillard, J. (1972). Black English. New York: Random House.

Fasold, R., \& Wolfram, W. (1970). Some linguistic features of Negro dialect. In R. Fasold \& R. Shuy (Eds.), Teaching Standard English in the inner-city (pp. 41-86). Washington, DC: Center for Applied Linguistics.

Fasold, R. W. (1981). The relation between black and white speech in the south. American Speech, 61, 163-187.

Johnson, S. C. (1967). Hierarchical clustering schemes. Psychometrika, 32, 241-254.

Klima, E., \& Bellugi, U. (1973). Syntactic regularities in the speech of children. In J. Lyons \& R. Wells (Eds.), Psycholinguistic papers. Edinburgh: Edinburgh University Press. (Original work published 1966).

Kovac, C. (1980). Children's acquisition of variable features. Unpublished doctoral dissertation, Georgetown University, Washington, DC.

Loe, L. (1974). Developmental sentence analysis. Evanston, IL. Northwestern University Press.

McNelli, D. (1970). The acquisition of language: The study of developmental psycholinguistics. New York: Harper \& Row.

Miller, J. (1981). Assessing language production in children. Baltimore: University Park Press.

Miller, W. R., \& Ervin-Tripp, S. M. (1973). The development of grammar in child language. Monograph of the Society for Research in Child Development, 29, $9-35$. (Original work published 1964).

Nelson, N. W. (1993). Childhood language disorders in context: Infancy through adolescence. New York: Macmillan.

Nelson, N. W., \& Hyter, Y. D. (1990). How to use Black English Sentence Scoring (BESS) as a tool of non-biased assessment. Short Course presented at the American Speech-Language-Hear- ing Association Annual Convention, Seattle, WA.

Ratusnik, D. L., \& Koenlgsknecht, R. A. (1976). Influence of age on black preschoolers' nonstandard performance of certain phonological and grammatical forms. Perceptual \& Motor Skills, 42, 199-206.

Reveron, W. W. (1978). The acquisition of four Black English morphological rules by Black preschool children. Unpublished doctoral dissertation, Ohio State University, Columbus.

Steffensen, M. (1974). The acquisition of Black English. Unpublished doctoral dissertation, University of Illinois, Evanston.

Stewart, W. (1970). Toward a history of American Negro dialects. in F. Williams (Ed.), Language and poverty. Chicago: Markham Publishing Co.

Stockman, I. (1984, September). The development of linguistic norms for nonmainstream populations. Paper presented at the National Conference on Concerns for Minority Groups in Communication Disorders, Vanderbilt University, Nashville, TN.

Stockman, I., \& Vaughn-Cooke, F. (1984, July). A closer look at the dynamic and static locative distinctions. Paper presented at the Third International Child Language Congress, Austin, TX.

Stockman, I., \& Vaughn-Cooke, F. (1982). A re-examination of research on the language of Black children: The need for a new framework. Journal of Education, 164, 157-172.

Stokes, N. H. (1976). A cross sectional study of the acquisition of negation structures in Black children. Unpublished doctoral dissertation, Georgetown University, Washington, DC.

Taylor, O. L. (1988). Speech and language differences and disorders of multicultural populations. In Handbook of speech-language pathology \& audiology (pp. 939-958). Philadelphia: D. C. Decker.

Taylor, O., \& Peters, C. (1976). Sociolinguistics and communication disorders. In A. Edwards (Ed.), Language in culture and class (pp. 802-818). London: Heinemann Brooks.

Terrell, S. L., \& Terrell, F. (1993). African-American Cultures. In D. E. Battle (Ed.), Communication disorders in multicultural populations. Stoneham, MA: Butterworth-Heinemann.

University of Michigan Institute for Soclal Research. (1989). Separate and unequal: The racial divide. Ann Arbor: Author.

U.S. Department of Commerce, Bureau of the Census. (1990). Statistical Abstract of the United States (110th ed.). Washington, DC: Author.

Washington, J., \& Craig, H. (1992). Articulation test performance of low-income, African-American preschoolers with communication impairments. Language, Speech, and Hearing Services in Schools, 23, 203-207.

Wilkinson, L. (1988). SYSTAT: The System for Statistics. Evanston, IL. SYSTAT, Inc.

Wolfram, W. (1971). Black and white speech differences revisited. In W. Wolfram \& N. Clarke (Eds.), Black-White speech relationships. Washington, DC: Center for Applied Linguistics.

Wolfram, W., \& Fasold, R. (1974). The study of social dialects in American English. New York: Prentice-Hall.

Wolfram, W. (1987). Are black and white vernaculars diverging? American Speech, 62, 40-48.

Woods, A., Fletcher, P., \& Hughes, A. (1986). Statistics in language studies. New York: Cambridge University Press.

Received June 11, 1993

Accepted January 12, 1994

Contact author: Julie A. Washington, PhD, Communicative Disorders Clinic, University of Michigan, 1111 E. Catherine Street, Ann Arbor, MI 48109-2054. E-mail: umich.cc.edu._juliewashington 